\title{
Etnoecologia indígena: saberes e fazeres culturais no cotidiano Tentehar ${ }^{1}$
}

\author{
Indigenous ethnoecologies: knowledges and cultural \\ everyday in Tentehar
}

\author{
Maria José Ribeiro de Sá \\ Maria das Graças Silva ${ }^{3}$
}

DOI: http://dx.doi.org/10.20435/tellus.v17i33.447

\begin{abstract}
Resumo: Descreve e analisa as culturas que informam a etnoecologia dos Tentehar, inscrita nos saberes e fazeres da vida cotidiana e na ancestralidade da Aldeia Indígena Juçaral, localizada na porção sudoeste da terra indígena Arariboia, situada no município de Amarante, MA. Visa ao conhecimento, à compreensão e à visibilização de seus saberes e práticas culturais como espaços de sociabilidade, reconhecimento da ancestralidade e da tradição oral por meio da análise reflexiva dos achados da pesquisa. Origina da seguinte questão de pesquisa: Que saberes culturais locais podem ser identificados nos processos e práticas sociais cotidianas dos Tentehar da aldeia Juçaral? A abordagem metodológica foi a qualitativa, com os procedimentos de uma pesquisa etnográfica aplicada à educação. A produção dos dados permitiu a construção de uma cartografia de saberes e práticas culturais presentes nesse cotidiano. Os resultados indicam que ainda é preservado um conjunto de saberes culturais relacionados à tradição oral dos Tentehar, sustentado numa relação de proximidade com os seres da natureza e em constante diálogo com o sobrenatural; na floresta, nas matas está fincada a base da sua vida material. Esses saberes podem ser observados nos seus diferentes rituais. Rituais que promovem o enraizamento cultural reatualizando eventos do cotidiano e regras culturais. Dessa forma, evocam a identidade cultural e o ethos dos Tentehar, em uma relação simbiótica entre natureza e a sobrenatureza.
\end{abstract}

Palavras-chave: etnoecologia; saberes culturais Tentehar; tradição oral; conhecimentos tradicionais.

Abstract: It describes and analyze the cultures that tells about Tentehar ethnoecology, inscribed in knowledges and everyday practices and in the ancestry of Juçaral indigenous land, located in Amarante city, Maranhão. It intends to

\footnotetext{
${ }^{1}$ Este estudo referencia-se na dissertação de mestrado em Educação, intitulada Saberes culturais Tentehar e Educação Escolar Indígena na Aldeia Juçaral (RIBEIRO DE SÁ, 2014).

${ }^{2}$ Instituto Federal de Ciência e Tecnologia do Maranhão, Imperatriz, Maranhão, Brasil.

${ }^{3}$ Universidade do Estado do Pará (UEPA), Belém, Pará, Brasil.
} 
understand the knowledge, comprehension and visibility of their knowledges and cultural practices as place of sociability, recognition of ancestry and oral tradition by reflexive analyzes of research findings. It begins with this question: What local cultural knowledges can be identified in Tentehar everyday process and practices from Juçaral? It was used a qualitative approach with the procedures of ethnography research applied to education. The production of data allows the construction of a cartography of knowledges and cultural practices present in daily life. The results indicate a group of knowledges related to Tentehar culture is still preserved, sustained by a relation of proximity with the nature and in constant dialogue with supernatural; in the forest, in nature is located the root of their material lives. These knowledges can be observed in their different rituals. Those rituals promote the cultural building reviving everyday moments and cultural rules. In this way, they evoke their cultural identity and Tentehar ethos, in a symbiosis relationship between nature and supernature.

Key words: ethnoecologies; Tentehar cultural knowledges; oral tradition; traditional knowledges.

\section{INTRODUÇÃO}

Este artigo trata das práticas culturais que informam a etnoecologia dos Tentehar, inscrita nos saberes e fazeres da vida cotidiana e na ancestralidade da Aldeia Indígena Juçaral, localizada na porção sudoeste da terra indígena Arariboia, situada no município de Amarante, MA. Apresenta um mapeamento desses saberes e dessas práticas presentes na cultura tentehar.

Os Tentehar se configuram atualmente como uma das maiores nações indígenas do Brasil e também do estado do Maranhão, onde são conhecidos pelo nome de Guajajara. Falam uma língua pertencente à família linguística tupi-guarani. Nesse estado, eles se distribuem em treze terras indígenas, que fazem parte das mesorregiões oeste e centro maranhense.

O estudo foi desenvolvido por meio de uma pesquisa qualitativa (GHEDIN; FRANCO, 2011), sustentada nos procedimentos da etnografia (GEERTZ, 2012) e da cartografia de saberes (OLIVEIRA; MOTA-NETO, 2011; SILVA, 2012), caracterizado ainda, como um estudo de caso (ANDRÉ, 2007). A pesquisa de campo foi realizada no período compreendido entre setembro de 2013 e setembro de 2014.

Para adentrar no universo simbólico dos Tentehar, foram utilizados como técnicas de produção de dados, três procedimentos: a observação participante (ANGROSINO, 2009), a entrevista semiestruturada (SZYMANSKI, 2004) e os registros visuais. 
Foram observados alguns rituais tentehar, como a festa de iniciação feminina, do moqueado e dos rapazes, mas, sobretudo, o ritual de apresentação da menina moça tentehar (festa do moqueado), por compreender que esse ritual se nutria da experiência vivida e agregava diferentes saberes culturais, ou seja, "os códigos simbólicos para interpretação e negociação dos eventos da vida cotidiana" (MCLAREN, 1992, p. 72), da Aldeia Juçaral. A entrevista semiestruturada foi realizada com dez moradores da aldeia, cujos critérios de seleção foram: a) vivência concreta no dia a dia, em algum dos saberes culturais mapeados, b) indicação de sujeitos escolhidos por membros da comunidade. Ainda de forma complementar, os registros visuais por meio de fotografias, feitas durante todo o trabalho de campo ${ }^{4}$, como técnica que pode ampliar os contornos das formas iconizadas da cartografia (MARTINS, 2008).

Inicialmente, esse texto trata dos saberes e fazeres tentehar, tomando como referência a conceituação de saberes em Brandão (2002; 2006), Charlot (2000) e Albuquerque (2012). Identifica que os saberes tentehar são um saber oral que acontece numa relação de proximidade com os seres da natureza e num constante diálogo com o sobrenatural. Na sequência, descreve detalhes dos seguintes saberes e fazeres tentehar: a prática cultural da caça; os saberes do cantar enquanto homenagem aos pássaros e animais da floresta; o saber tecer adornos corporais e diferentes utensílios domésticos das mulheres Tentehar; e o saber das pinturas corporais com o uso do jenipapo.

As considerações finais apresentam como os Tentehar, um dos povos das florestas, têm a base da sua vida material e religiosa fincada nas matas, na natureza (ZANNONI, 1999). Assim, na relação direta com a floresta, os Tentehar constroem uma ampla rede de saberes e práticas culturais, muitos deles são tomados como referências para explicar fatos do dia a dia, como o nascimento, a passagem da fase de criança à adulta, ou ainda o sofrimento, a doença e a morte. Esses saberes podem ser observados nos seus diferentes rituais. Os seus rituais promovem o enraizamento cultural reatualizando eventos do cotidiano e regras culturais. Dessa forma, evocam a identidade cultural e o ethos dos Tentehar, tecidos na relação simbiótica entre natureza e a sobrenatureza.

\footnotetext{
${ }^{4}$ Em observação aos aspectos éticos da pesquisa, foi solicitada a autorização do estudo para a comunidade, e esta foi assinada pelo cacique da aldeia. Para os registros orais e visuais, foi feita a leitura do termo de consentimento livre e esclarecido e solicitada a autorização dos intérpretes.
} 


\section{CARTOGRAFIA DOS SABERES E FAZERES TENTEHAR}

No imaginário tentehar, seus cantos e danças, seus ritos e suas crenças, configuram diferentes códigos e gramáticas, que ordenam a própria vida social. Como nos diz Brandão (2002), funcionam como mapas simbólicos de roteiros de preceitos e princípios que constituem a sua cultura. De acordo com Brandão (2006), é com as práticas sociopedagógicas do dia a dia que as gerações adultas, ou seja, homens, mulheres, velhos, artesãos, feiticeiros, etc. ensinam crianças e jovens. Assim, os que sabem fazem; ensinam, vigiam, incentivam, demonstram, corrigem. Os que não sabem são instruídos com o exemplo, veem, imitam, aprendem com especialistas valores, imaginários, crenças. Existe, portanto, uma intrínseca relação entre cultura e educação. Educar e aprender faz parte da dinâmica da vida. Para Brandão (2002, p. 26), a educação resulta em processos de "interação de saberes em graus e modos sempre amplos e profundos".

A esse respeito reconhece Charlot (2000, p. 63) que o saber é uma relação, ou seja, "o saber é construído em uma história coletiva". Dessa forma, eles decorrem de construções coletivas experienciais. Os saberes são, portanto, formas de entender, descrever e explicar a realidade coletivamente.

Neste trabalho, a ideia de saberes culturais está associada a uma "forma singular de inteligibilidade do real fincada na cultura, com a qual determinados grupos reinventam o cotidiano, criam estratégias de sobrevivência, transmitem seus saberes e perpetuam seus valores e tradições" (ALBUQUERQUE, 2012, p. 24).

Entre os Tentehar da Aldeia Juçaral, é tradicional a transmissão dos saberes e práticas culturais locais por meio do ato de contar e ouvir histórias. Os velhos, através da prática de contação de histórias que tratam de suas reminiscências, ensinam o que aprenderam com seus ancestrais.

A busca por manter as práticas do passado no presente é uma estratégia de manterem vivos na memória os saberes culturais que esse povo construiu historicamente por meio de múltiplas atividades cotidianas que os Tentehar desenvolvem no complexo natural roça-mata-rio-igarapé-quintal (LOUREIRO, 1992). É, portanto, na floresta, por meio de práticas cotidianas, que tradicionalmente aprendem e dão sentido aos seus modos de viver e praticam suas diferentes formas culturais. Como povo originário das florestas, a base da vida material e religiosa dos Tentehar está nas matas, na natureza. 
Zapuy Guajajara (62 anos, cacique da aldeia Juçaral na ocasião da pesquisa) afirma que a mata é mãe da gente, a vida da gente, reconhece que a mata, segundo a ancestralidade Tentehar, é um espaço vital para a reprodução da vida simbólica e material. Nessa perspectiva, a mata assume diferentes funções nesse processo de reprodução: pode ser um lugar para a prática da caça, da coleta de plantas curativas, e também como espaço de proteção dos infortúnios; é ainda o lugar de onde retiram os enfeites e as tinturas para celebrar suas festas, o que na sua essência configura uma celebração da vida. Portanto é um espaço que abriga múltiplos saberes, imaginários, representações e práticas.

\subsection{A prática cultural da caça}

Como são originados os saberes e práticas culturais dos Tentehar? De acordo com o índio tentehar Vicente Guajajara (93 anos), esses saberes vieram dos encantados, pois foram eles que ensinaram o seu povo a viver harmonicamente com a natureza.

A caça é uma dessas práticas culturais. Entre os Tentehar, é uma atividade restrita aos homens. A mata, enquanto espaço da caçada, é tida como um ambiente perigoso e imprevisível, visto que, na mata, os espíritos bons e maus da floresta podem se transformar em gente e animais: gente pode se transformar em animais, ou ainda animais podem se transformar em gente.

Segundo Viveiros de Castro (2002), a situação sobrenatural típica do mundo ameríndio é o encontro na floresta, em que um humano sozinho, visto como mero animal ou pessoa, revela-se "como um espírito ou um morto". Esse encontro, portanto, pode ser letal, o caçador, por exemplo, subjugado pelo espírito, pode se transformar em um ser da mesma espécie, "morto, espírito ou animal" (VIVEIROS DE CASTRO, 2002, p. 397).

Nessa perspectiva, o cacique Zapuy Guajajara explicou que o caçador precisa ficar atento para saber se a caça que ele matou não tinha algum espírito, pois as pessoas quando em vida aqui na terra que fizeram o mau, ao morrerem ficam perambulando como espíritos; caso o caçador mate uma caça que tenha espírito do mau, ele fica enfeitiçado e pode até morrer.

Quando ele fica fazendo doença assim, é porque ele não vai pra casa do nosso pai, e fica perambulando em cima dessa terra. Ele vira mucura, ele vira raposa, ele vai virando qualquer dessa coisa, só pra fazer essas coisa ainda, ele ainda vira veado, catitu. Ai quando a gente atira nela e sai aquele fogo, daí aquela outra pessoa fica doente, eu atirei num catitu ou então no veado e acendeu o fogo, se o índio é 
caçador a caça vai dar feitiço pra ele, caçador de guariba, a guariba vai dar feitiço praquele índio, é assim que a doença acontece na gente. (ZAPUY GUAJAJARA).

Nesse sentido, há uma aproximação entre a prática da caça e a prática de um pajé/ xamã, porque ambas exigem habilidades e saberes para dialogar com os espíritos que circulam na mata. O sucesso da atividade dependerá tanto da satisfação dos critérios/ desejos impostos pelos espíritos donos, quanto do saber diferenciar múltiplos espíritos.

Para Viveiros de Castro (2002, p. 357) a "valorização simbólica da caça" e o "xamanismo" são duas características recorrentes na Amazônia. De acordo com o autor, mais do que uma dependência ecológica, a caça possui uma ressonância simbólica. À arte de caçar é atribuída um peso cosmológico, que decorre da "subjetivação espiritual dos animais, e à teoria que o universo é povoado de intencionalidades extra-humanas" (VIVEIROS DE CASTRO, 2002, p. 357).

A mata e o rio são elementos dos ecossistemas naturais, porém ricos em significações culturais, que conformam um conjunto de crenças e concepções que orientam a vida e as ações dos habitantes dos rios e das matas na Amazônia. Ao falar poeticamente sobre a Amazônia como uma encantaria do mundo, lugar de paisagens ideais com rios e florestas habitadas por diferentes seres encantados, diz Loureiro ${ }^{5}$ (2008, p. 359): "a floresta nasce de uma semente que brota no útero da terra. Uma floresta é também uma plantação de símbolos".

Espíritos encantados das florestas como o boto, a cobra grande, a iara, a matinta, mãe d'água, por exemplo, segundo Fares (2008, p. 89), "aparecem em narrativas fundadoras da região, inferem saberes sobre a Amazônia e constroem a história da região". Esses personagens, explicam Rodrigues et al. (2007, p. 34), enquanto "habitantes das águas e matas fazem com que o meio ambiente incorpore mais que uma noção funcional e de matéria-prima abundante, constituindo-se em um espaço simbólico e do imaginário" ${ }^{6}$.

No imaginário tentehar, o Caipora ${ }^{7}$ é um, entre uma variedade de seres sobrenaturais que circulam em narrações lendárias e mitológicas que são parte constituinte

\footnotetext{
${ }^{5}$ João de Jesus Paes Loureiro é poeta e professor de Estética, História da Arte e Cultura Amazônica, na Universidade Federal do Pará.

6 "Criação incessante e essencialmente indeterminada (social-histórica-psíquica) de figura/formas/ imagens, a partir das quais somente é possível falar de alguma coisa" (CASTORIADIS, 1982, p. 13).

${ }^{7}$ De acordo com Cascudo (2012, p. 158), no imaginário amazônico, o “Curupira é um caapora, residindo no interior das matas, nos troncos das velhas árvores. De defensor das árvores passou a protetor da caça [...] no Maranhão para o Sul o Caipora é o tapuia escuro e rápido".
} 
do imaginário amazônico. O Caipora é descrito como homem baixinho, o baixim, o anãozim, que tem os pés virados para trás, afirma Zapuy Guajajara. Para os Tentehar, ele é tanto o dono das matas, como das caças, o Caipora, o dono caça, caboquim vei baixo, mas tem força demais, é uma fera, é o dono da caça, segundo João Tawi Guajajara. A palavra dono representa a posse ou responsabilidade pelo recurso natural do qual o espírito controla o uso; no caso de Caipora, para os Tentehar, ele controla o uso das matas e das caças que nelas habitam. O Caipora é um ser invisível, um encantado da floresta. Só os homens com verdadeiro espírito de caçador conseguem vê-lo, por isso, engana facilmente os Tentehar, pois com facilidade ele se metamorfoseia e se transforma tanto em gente como em bicho. Na visão de Viveiros de Castro (2002, p. 72), "a metamorfose reintroduz o excesso e a imprevisibilidade na ordem do socius, transformando os homens em animais ou espíritos".

Na tradição Tentehar, antes de ir para a caçada, o caçador deve pedir permissão para o Caipora, por isso os caçadores tentehar estão sempre preocupados em não caçar mais que o necessário, visto que as sanções do Caipora são severas àqueles que desperdiçam a caça, ou que ainda retiram madeira da floresta sem antes pedir autorização. Geralmente, são punidos com doenças, ou ainda com a morte para sanções gravíssimas. Segundo relatou João Tawi Guajajara, um grupo de caçadores foi morto pelo Caipora, porque eram incrédulos quanto à existência dessa entidade na mata, e assim puseram-se a matar muitos animais sem a prévia autorização do Caipora. Como punição, o Caipora devorou todos os caçadores, restando somente a cabeça de um deles que seria um pajé, mas que no dia seguinte se transformou num gavião real. De acordo com Zannoni (1999, p. 132), “O Caipora (Miar'i'zar), que protege os animais, tem o poder de se transformar neles e aparecer o caçador. Caso este atire e a caça não morra, esta começa chorar como gente, e o caçador adoece. Isso acontece quando o caçador não está preparado, ou transgrediu alguma regra, ou matou caças além do permitido".

Assim, para os Tentehar, a prática da caça, como bem explicitou Zannoni (1999, p. 131), está "estritamente ligada ao sobrenatural e repleta de regras culturais". As regras culturais se fazem notar nos tabus alimentares, como a introdução de carnes na alimentação da criança, ou ainda proibição de determinadas caças em diferentes etapas da vida ${ }^{8}$. Como exemplo, cita-se a regra relatada por Zapuy Guajajara, referindo-se ao pai de um recém-nascido, diz: só depois que cai umbigo, ele pode caçar;

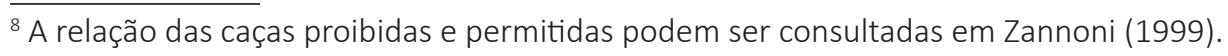


ele caça só aquela cutia, veado. Não pode balear também não! se balear e morrer longe, a criança vai vomitar. Como se pode notar, tratam-se de regras culturais que extrapolam as necessidades exclusivamente nutritivas. Na sua dimensão simbólica, revelam situações sociais e culturais. Para Albuquerque (2012, p. 33), "a alimentação expressa escolhas culturais configurando-se, portanto, como elemento essencial da estruturação social dos grupos e de expressão de identidades".

O moqueado, a carne de caça defumada logo após a caçada, é uma prática alimentar que vem da ancestralidade tentehar. O fruto da caçada, a carne moqueada, possui uma dimensão simbólica muito forte entre os Tentehar; ela está presente no seu principal ritual, a festa da menina moça, também conhecida como festa do moqueado $^{9}$ (figura 1).



Figura 1 - Distribuição dos bolos de carne moqueada na festa do moqueado Fonte: Acervo fotográfico de Maria José Ribeiro de Sá (2014).

\footnotetext{
${ }^{9}$ Moquear diz respeito a prática cultural ameríndia de assar a carne de caça sobre um jirau (grelhas de pau) em fogo lento.
} 
A carne de caça moqueada está presente como o principal alimento do início ao fim do ritual de apresentação da menina moça para a comunidade. O início do ritual começa com a ida à mata pelos homens para buscar a caça e moqueá-la, e o seu encerramento é marcado pela distribuição de pequenos bolos de carne moqueada pela menina moça, que são disputados por toda a comunidade.

Por meio da festa de moqueado, a prática alimentar da carne de caça moqueada se mantém viva até os dias atuais entre os Tentehar da Aldeia Juçaral. O moqueado tem o poder de ativar o imaginário tentehar, de transmitir saberes e valores que circulam no espaço híbrido da floresta.

Entre muitos significados, o moqueado, na minha percepção, contém em essência, o fluído vital, que permite e dá sentido à vida que subjaz ao ethos tentehar, a busca de uma relação simbiótica entre natureza e sobrenatureza. Assim, na mata, o caçador precisa vencer a natureza e a sobrenatureza, necessita de alguns saberes práticos, o bom caçador se revela pela sua perspicácia, pois na mata, ele precisa saber reconhecer o lugar por onde entrou e deve sair, ele olha para o sol, ele sabe controlar tudo, explicou Toinho Guajajara (36 anos); caso não saiba fazer esse controle, ele pode se perder na mata, e ficar rodando, ressaltou. Entre as estratégias para enganar os bichos, está a de andar com um cipó sempre atrás de si, para fazer os bichos pensarem que é cobra, e assim se afastarem, afirmou Toinho Guajajara.

Outro saber que revela essa interconexão muito forte entre os Tentehar, os espíritos e os animais da floresta, é o saber cantar.

\subsection{O saber cantar: homenagem aos pássaros e animais da floresta}

No imaginário tentehar, cada etapa da vida vencida, seja no nascimento, ou na passagem da fase de criança à adulta (quando as meninas estão prontas para fazer nascer a vida e dela cuidar; e os rapazes para serem guerreiros caçadores, cantores ou pajés e assim garantir o sustento), cada colheita de onde brota o alimento, seja com o mel colhido do tronco de uma árvore, ou ainda na roça de milho ou maniva, são motivos para celebrar e reverenciar os espíritos e a natureza pela graça da vida.

Os rituais configuram-se como celebração. Os seus cantos trazem narrativas de estórias vividas entre eles e os diversos animais presentes nos ecossistemas de suas matas. Segundo o que relatou o índio tentehar Toinho Guajajara, que é cantor, todo cântico tem uma história envolvendo o animal que está sendo cantado na festa. O ritual da festa dos rapazes, por exemplo, surgiu em decorrência da história 
mítico-lendária de um rapaz Tentehar que fora abandonado pelo irmão em cima de uma árvore e que, na convivência com os gaviões que o adotaram, acabou se transformando em um gavião, um pajé gavião, assim, transformava-se em índio ou em gavião. Consequentemente, o dono da festa dos rapazes é o gavião. Nessa festa, além do gavião também cantam tumuzu'hu (um espírito) e a onça.

Por sua vez, os cânticos entoados na festa da menina moça homenageiam aves, como a arara ${ }^{10}$, papagaio, jaó ${ }^{11}$ ou lambu tona; e alguns mamíferos como o macaco guariba e o macaco prego. A ave lambu tona é a dona da festa da menina moça. Já os cânticos da festa do mel, falam de mel e de abelhas, das onças e de outros animais, como o jabuti, o macaco cuxiú, o esquilo, o porco queixada, o porco caititu, a arara, a lontra, o jacamim, o quati, a curica (papagainho), etc.

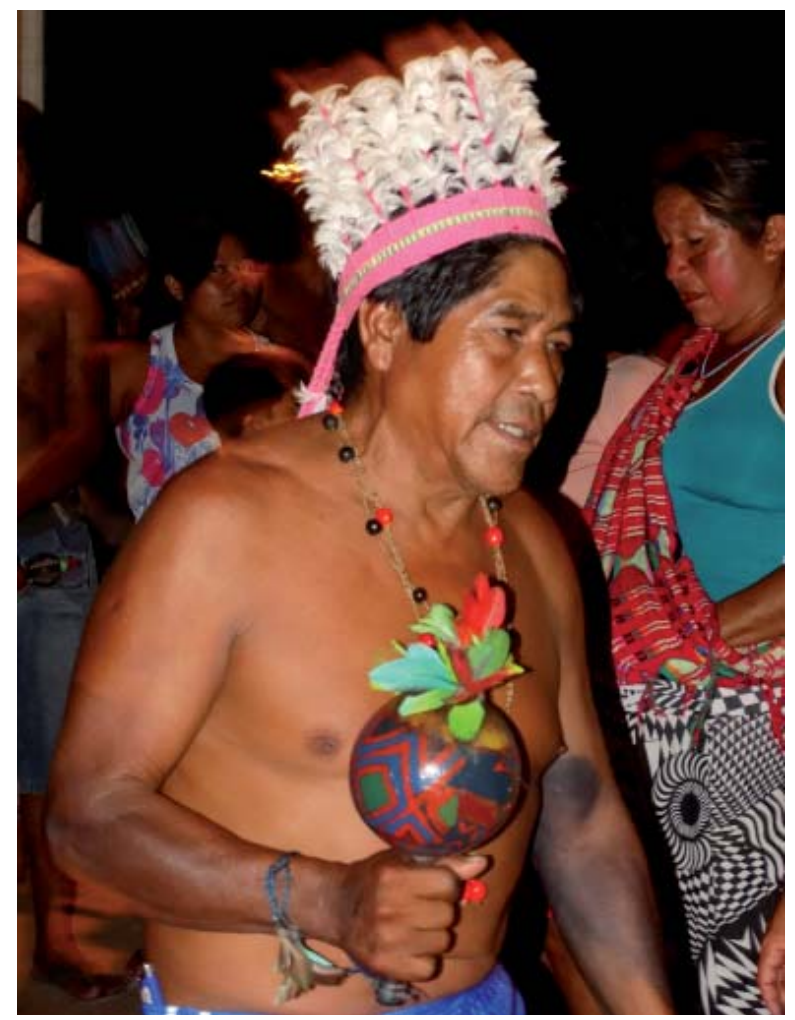

Figura 2 - Cantor tradicional Tentehar

Fonte: Acervo fotográfico de Maria José Ribeiro de Sá (2014).

\footnotetext{
${ }_{10}$ O canto da arara anuncia notícias de acordo com Zannoni (1999).

11 O Jaó de pé roxo (lambu tona) "é considerado um pássaro que tem o poder de acabar com todos os encantos" (ZANNONI, 1999, p. 31).
} 
A cantoria inicia-se em frente da casa de um cantor (figura 2), geralmente do cantor mais velho. Os cantores convidados para a festa, ao chegarem, se posicionam um ao lado do outro, segurando à mão o seu maracá e portando na cabeça o seu capacete. Todos já posicionados combinam entre si, quem iniciará a cantoria ${ }^{12}$. Um deles inicia, em voz baixa, agitando o seu maracá para que os outros cantores o acompanhem. Os cantos são longos, e as estrofes se repetem diversas vezes, como anotou Zannoni (1999, p. 27):

São cantos compridos nos quais varia somente a parte inicial, que é cantada pelo cantor e repetida por todos os outros, e em seguida pelo refrão, igual durante todo o canto. As mulheres cantam em falsete, [...] com um tom de voz uma oitava acima do canto dos homens, acompanhando seu canto os monossílabos: he, he, he.

Os cantores detêm boa parte do patrimônio cultural imaterial desse povo, visto que carregam consigo na memória várias narrativas mítico-lendárias do imaginário tentehar que explicam a origem de cada ritual, nos muitos cânticos que compõem o repertório de cada festa. Os cantos são entoados ao som do único instrumento que utilizam em suas festas, os maracás. O maracá, por sua vez:

É um instrumento que só mestre pode pegar. Aqueles que não tão preparado, não pode pegar. Menino não pode pegar, só quando faz a festa deles, é que depois ele pode pegar, pra aprender a cantar. O maracá é sagrado, não é todos que podem pegar não. (TOINHO GUAJAJARA).

Utilizado para acompanhar os cânticos, o maracá simboliza a voz dos espíritos. Por isso, é considerado um instrumento sagrado, e tradicionalmente só os cantores podem fazer uso destes nos rituais. Usar o maracá exige preparação prévia por meio dos cantos, pois reza a tradição, que "a primeira vez que uma pessoa o pega, sente um choque" (ZANNONI, 1999, p. 30).

Os rapazes são iniciados oficialmente nas atividades de cantoria, caça/guerra e pajelança no ritual de iniciação masculina, visto que as práticas que exigem conexão com o sobrenatural estão restritas aos homens. Como Barros e Zannoni (2010, p.3) comentam:

É por isso que, na festa de iniciação masculina [...] ele deve aprender a controlar os espíritos, a cantar com o maracá, a ser caçador e pajé ao mesmo tempo. Ao

\footnotetext{
${ }^{12}$ Embora seja indispensável a presença de mestres de cantorias para execução de toda a festa, outros cantores colaboram também cantando o que sabem.
} 
entrar em contato com o mundo sobrenatural ele adquiriu poderes para mediar o relacionamento com esse mundo inacessível aos não iniciados e às mulheres.

A festa dos rapazes, diferente da festa da menina moça, cuja referência para a sua realização é a primeira menstruação, não tem um período certo para ser realizada. A festa dos rapazes é realizada anualmente em muitas aldeias, sem que haja um período certo, devido à dificuldade dos cantos, ou até mesmo, à falta de recursos financeiros para uma aldeia custear duas festas no mesmo ano. Portanto, é um ritual pouco realizado na TI Arariboia, explicou Toinho Guajajara. De acordo com Zannoni (1999), na TI Pindaré, as duas festas, dos rapazes e das moças, são feitas concomitantemente.

Para ser um cantor, a atividade mnésica é fundamental, reconhece Toinho Guajajara. Além de boa memória e voz, saber ouvir é outro atributo indispensável. É por meio da prática do ouvir que ele aprende e, ao mesmo tempo, ganha a confiança dos mestres cantores. Assim, saber cantar passa por uma necessária educação dos sentidos e da mente. De acordo com Munduruku (2012, p. 71), ao se referir sob a epistemologia do pensar indígena, é "através do ato de ouvir histórias, contadas pelos guardiões da memória", que sua gente educa sua mente.

Dessa forma, é possível afirmar que é por meio da educação dos sentidos e das mentes que os mestres de cantorias tentehar preparam seus cantores e entregam a eles a responsabilidade de transmitir os saberes culturais para as gerações que virão, pois, a educação.

É condição da permanente recriação da própria da cultura, individualmente a educação, uma relação entre trocas de pessoas, é condição da criação da própria pessoa. Aprender significa tornar-se, sobre o organismo, uma pessoa, ou seja, realizar em cada experiência humana e individual a passagem da natureza à cultura. (BRANDÃO, 2006, p. 22).

Se, entre os Tentehar, os saberes do cantar se configuram culturalmente como uma atividade predominantemente masculina, o saber fazer diferentes utensílios com intermédio dos recursos naturais existentes na terra indígena Arariboia, por sua vez, é uma prática cultural própria do universo feminino.

\subsection{O saber tecer: das plantas às utilidades para o dia a dia}

Seus móveis caseiros são as redes de algodão a que chamam de ini. Prendem-nas pelas extremidades, com cordas torcidas, também de algodão, que amarram 
a pedaços de pau para esse fim, colocadas nas choupanas. Cada um tem sua rede [...] Têm cestos a que chamam uru ou caramemô. São feitos de folhas de palmeiras ou de pequenos juncos lindamente tecidos. (ABBEVILLE, 2008, p. 303).

A arte e as maneiras de fazer das artesãs da aldeia Juçaral estão configuradas no saber fazer redes, bolsas, roupas tradicionais e cestarias. As redes e as cestarias fazem parte da cultura material tradicional do povo tupi. Como mostrou Abbeville (2008), as redes e cestas compunham o mobiliário dos Tupinambá no Brasil colonial. Elas ainda são feitas pelos Tentehar da aldeia Juçaral até os dias de hoje, com o mesmo instrumental de seus ancestrais, de acordo com o autor citado. A linha utilizada para fabricação das redes, na atualidade, é comprada no comércio, mas até bem pouco tempo, segundo explica Angelina Guajajara (72 anos), as índias tinham o costume de produzir a linha de algodão.

De primeiro fiava com algodão, agora já compra a linha feita. Colhia na roça, trazia, tirava a semente, abria, dava mais trabalho e tempo. Depois que tirava a semente tinha que botar num saco, batia para ficar fininho, ai ela ia rasgando para fazer o fio, e tirar fazer o círculo rodando para colocar no fuso. (ANGELINA GUAJAJARA).

Mas as redes continuam a ser tecidas no tradicional tear. O tear é uma armação de dois paus dispostos lateralmente com distância aproximada de dois metros, presos ao chão verticalmente, que, na parte de cima, se abre em dois ramos, assumindo a forma da letra Y, uma forquilha. Nas forquilhas são presos dois pedaços de pau na horizontal, um em cima e outro em baixo, onde os fios de algodão serão presos. No plano de cima, junto ao pau, é preso um talo de inajá, que serve para fazer os punhos; e, no centro, para dar forma aos desenhos estampados na rede, é colocado entre os fios um talo de buriti. Há ainda outros dois instrumentos que colaboram na tessitura das redes, que são o fuso e uma faca de pau. O tear, por sua vez, faz parte da cultura material desse povo, ele não se modificou, considerando a descrição de Abbeville (2008) em 1614 sobre seu uso pelos Tupinambá, ou ainda de Wagley e Galvão (1961) quando etnografaram a cultura tentehar.

Angelina Guajajara aprendeu a tecer redes, tipoias. Foi por ocasião da sua primeira menstruação, no seu ritual de iniciação, quando estava presa na tocaia ${ }^{13}$,

${ }^{13}$ É uma espécie de casa ou abrigo que o caçador tentehar faz na mata com galhos de árvores para abrigar a si e as caças. Além de representar simbolicamente o local de reclusão ou interdição da jovem mulher nos rituais de iniciação e apresentação feminina desse povo. 
que sua mãe Ihe ensinou o processo de fiar o algodão e depois da saída continuou a ensinar a fazer as redes, pois, no ritual de iniciação feminina tentehar, a jovem fica reclusa dentro de casa por, aproximadamente, sete dias, período em que a mãe ensinará a filha diferentes afazeres do lar. No exercício cultural do cotidiano feminino, desde a juventude, ao tecer redes e tipoias, Angelina aprendeu habilidades manuais, ao manipular o algodão ou as linhas no tear para dar forma as redes e tipoias; além disso, desenvolveu o sentimento de ser uma mãe cuidadora dos filhos e do lar. Hoje, tem um ofício e sabe ensiná-lo às filhas e netas. Portanto, a prática de tecer confirma aquilo que Brandão (2002, p. 24) refletiu sobre uma determinada cultura: "viver uma cultura é conviver com e dentro de um tecido de que somos e criamos, ao mesmo tempo, os fios, o pano, as cores o desenho do bordado e o tecelão".

Foi por meio do ensinar a manipular o tear repassado de mãe para filha que dona Angelina Guajajara aprendeu os diferentes saberes que informam a prática de tecer, como por exemplo: as redes feitas com duas pernas de fio são para os solteiros; aquelas reforçadas, com três fios são para adultos; o trançado que dá forma aos desenhos tem um lado macio onde se deita, e outro, mais áspero; a forma geométrica de quadrado é geralmente feita para mulheres e as retangulares para os homens.

No tear, além de redes, que servem para o sono e o descanso do corpo, as mulheres/mães tentehar produzem suas tradicionais tipoias, instrumento que serve para trazer junto de si os filhos, aproximadamente até os dois anos de idade. A tipoia, simbolicamente, expressa o amor e o cuidado que as mães indígenas têm por seus filhos (figura 3). Abbeville (2008, p. 302) comenta: "É impossível dizer a que ponto amam seus filhos apaixonadamente. Jamais os abandonam e trazem-nos consigo sempre em sua companhia, [...] carregam o menino suspenso ao pescoço por um pedaço de pano de algodão". 




Figura 3 - Mãe Tentehar

Fonte: Acervo fotográfico de Maria José Ribeiro de Sá (2014).

É por meio do tear que as mulheres Tentehar também tecem a estrutura que recebe as penas nos capacetes, braceletes e tornozeleiras, e ainda diferentes modelos de bolsas, mochilas, que servem não só para diversos usos diários, como também para levar e trazer material escolar, notebooks, ou portar documentos, e também comercializá-los.

As cestarias são outro tipo de artesanato que mantêm a originalidade dos saberes ancestrais Tentehar. É na natureza, ao fundo de seu quintal, uma área alagadiça sobre as sombras dos altos buritizais que margeiam o rio Buriticupu, que Maria Parazawu (46 anos) colhe o principal instrumento para confecção das cestarias que faz, o guarumã ${ }^{14}$.

\footnotetext{
${ }^{14}$ Planta amazônica marantácea (Calatea juncea) que habita lugares úmidos, usado pelos indígenas e ribeirinhos para confecção de artesanato, pois contem fibras em sua composição (PANTOJA et al., 2015).
} 
Confiante de que o guarumã e o buriti1 ${ }^{15}$, as duas principais matérias primas que utiliza para fabricar suas cestarias, são doação divina, tecer é uma forma expressar agradecimento a Deus. Assim, reconhece Maria Parazawu, argumentando que é preciso conservar esses vegetais na natureza, ou seja, produzir somente o necessário ou o que vai utilizar, de modo que esse bem natural não seja extinto.

A produção de cestarias é uma arte considerada difícil, pois, segundo informações locais, são poucos os Tentehar que ainda dominam essa técnica. Atualmente, na aldeia Juçaral e nas aldeias próximas, apenas Maria Parazawu, o marido que a ajuda e um irmão é que sabem fazer cestarias.

Com o saber que veio dos seus antepassados, Maria Parazawu, com uma simples faca amolada e arame na mão, cria novos sentidos e significados para talos e palhas de palmeiras nativas, que se fazem presentes até hoje entre as novas gerações, ao transformar o guarumã e o buriti em variados tipos de cestos. 0 tapiti, por exemplo, é um tipo de cestaria que incorpora o saber preparar a massa de mandioca, usado por indígenas e ribeirinhos para escorrer e secar a mandioca ralada; já a esteira de babaçu é utilizada por rapazes e moças para se protegerem dos maus espíritos, nos respectivos rituais. Assim, "a natureza é feita de maneira ser mais vantajosa para a ação e o pensamento agir como se uma equivalência que satisfaz o sentimento estético correspondesse também a uma realidade objetiva" (LÉVI-STRAUSS, 1979, p. 31).

Desse modo, destacam-se as muitas vantagens da convivência com a natureza. Por meio da fauna e da flora da TI Arariboia, os Tentehar da aldeia Juçaral continuam a buscar o saber proteger-se e curar-se dos males espirituais e físicos que estão à espreita de atingirem seus corpos. Por isso, o saber das pinturas corporais com o jenipapo é indispensável para essa proteção, conforme descrição a seguir.

\subsection{O saber das pinturas corporais: uso do jenipapo}

A nota de número quarenta e cinco do livro "A história das coisas mais memoráveis acontecidas no Maranhão nos anos de 1613 e 1614", as tinturas vegetais com que os povos ameríndios costumavam pintar seus corpos:

${ }^{15}$ O buriti ou miriti (Mauritia flexuosa) é uma planta de ampla distribuição nacional que habita terrenos alagáveis e brejos de várias formações, sendo encontrada com muita frequência nas veredas (CERRATINGA, s.d.). 
Em toda a América meridional costumavam os selvagens tingir a pele de vermeIho-alaranjado, ou de negro-azulado por meio do rocou, Bixia orellana, ou do jenipapeiro (Genipa americana). O P. Ives, descrevendo com exatidão os frutos desta árvore, em abundância no Maranhão, diz - o sumo claro límpido que se extrai dela, fica muito negro logo depois da sua aplicação, e assim conserva-se por debaixo d'agua, por 9 dias. (ABBEVILE, 2008, p. 395).

É com a tintura preto-azulada do jenipapeiro que os Tentehar costumam pintar os corpos. Para extrair o pigmento, os Tentehar ralam o fruto, tiram uma água que, exposta ao sol, em pouco tempo servirá como tintura. De acordo com Fred Guajajara (33 anos), os Guajajara usa mais é jenipapo, os Gavião, os grupos Jê, usam mais é urucum. Embora também se pintem com urucum, principalmente em dias comemorativos, como registrou Zannoni (1999), na festa dos rapazes, ocasião em que prepara também "suco de jenipapo e urucu para as pinturas corporais". As duas tinturas, urucum e jenipapo, ainda são usadas em movimentos e manifestações por reivindicação de direitos indígenas, a gente usa completo, jenipapo e urucum, afirmou Fred Guajajara.

Geralmente, todos aprendem a fazer a tintura e a se pintar observando como se pintam uns aos outros. Analisando esse fato, com base em Brandão (2006), pode-se dizer que "o saber flui, pelos atos de quem sabe-e-faz, para quem não-sabe-e-aprende". O pintar o corpo se configura assim, como um momento especial de ensinar e aprender, de transmitir um saber fazer. A criança ou o jovem ao ver um adulto pintar o corpo, "imita e aprende com a sabedoria que existe no próprio gesto de fazer a coisa" (BRANDÃO, 2006. p. 18). O gesto de pintar o corpo, por sua vez, consiste em pegar um talo de buriti com algodão imerso na tintura de jenipapo, levá-lo ao corpo, e contorná-lo com todo o cuidado para a perfeita simetria das formas desenhadas.

Sobre o uso da pintura corporal no cotidiano, Fred Guajajara comentou: "de criança, a gente pinta o corpo todinho. Quando adulto, vai se pintar normal, é igual, as mulheres, a menina moça, dali que ela vai se pintar, a pintura completa tem as regras".

Ao aprender a pintar o corpo em diferentes situações do dia a dia, sem qualquer imposição, as crianças Tentehar aprendem a ter consciência de si e do seu corpo. É pela aprendizagem na convivência comunitária, do uso de todos os sentidos, que a criança vai preenchendo as lacunas do seu corpo, dando sentido ao seu existir. Assim, as crianças aprendem desde cedo que o corpo é sagrado, mas que possui ausências que precisam ser preenchidas (MUNDURUKU, 2012).

Logo cedo, aos oito meses de vida, conforme registrou Zannoni (1999), a criança Tentehar tem a primeira festa de iniciação, e um dos ritos consiste em passar a tintura 
de jenipapo no seu corpo. A pintura corporal, acompanhada das regras culturais, marca as diferentes etapas da vida dos Tentehar. Assim é porque, de acordo com Viveiros de Castro (2002, p. 387), a corporalidade, o corpo nas sociedades amazônicas tem um fundamento cosmológico, cujas "categorias de identidade - individuais, coletivas, étnicas ou cosmológicas", expressam-se frequentemente por meio de idiomas corporais, particularmente, pela alimentação e decoração corporal.

A decoração corporal feita pelos Tentehar inspira-se na biodiversidade, como a cobra jiboia, peixes, pássaros e outros animais silvestres. Eles se inspiram nas formas impressas no corpo desses animais para os seus, de acordo com Fred Guajajara. Nesse sentido, Viveiros de Castro (2002, p. 388) explica que, na etnologia e mitologias amazônicas, o modelo de adorno do corpo está pautado nos corpos animais. Esse autor, ao falar da decoração e exibição ritual, diz que elas representam ao mesmo tempo a "objetivação social máxima dos corpos" e a sua "máxima animalização" (figura 4).

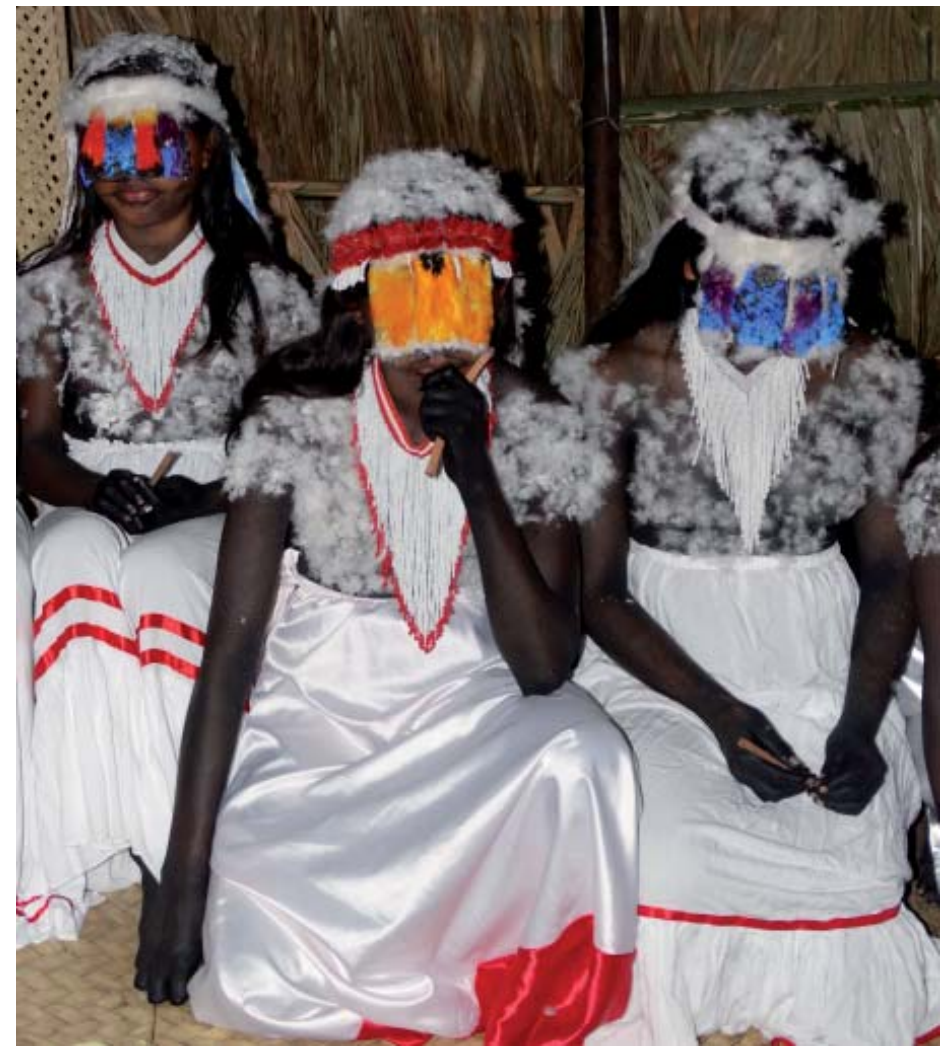

Figura 4 - Decoração corporal das meninas moças Fonte: Acervo fotográfico de Maria José Ribeiro de Sá (2014). 
A inscrição nos seus corpos, com tipos e formas específicas, marca as metamorfoses corporal e social que os Tentehar vivem em seus rituais de passagem, conforme se percebe na reflexão a seguir: "quando a moça é colocada na tocaia, [...] é despojada de todo tipo de roupa, é pintada com o sumo de jenipapo, do rosto aos pés. Em seguida, toda a família pinta-se, também, com esse suco" (ZANNONI, 1999, p. 64).

Por meio do pintar o corpo com a água do jenipapo concomitante ao cumprimento das regras culturais, os adultos ensinam aos jovens o saber cuidar do corpo e proteger-se das doenças físicas e espirituais. "A gente se protege das doenças", afirmou Fred Guajajara, ao comentar a importância do pintar o corpo com o jenipapo como uma forma de prevenir as doenças. O jenipapo também serve para a cura espiritual, quando o corpo está doente. Ao falar sobre uma mensagem transmitida por Deus em sonho, Zapuy Guajajara explicita a função do jenipapo numa festa em que os Tentehar pedem a cura de doenças - a mesada: "Eu teve esse sonho também, que Deus orientou eu. Nós índio disse (Deus), a gente tem que usar é jenipapo. Deus disse: quando tem gente que faz a mesada pro povo tudo. Vocês têm que tirar a água preta. Aí pensei assim: é o jenipapo" (ZAPUY GUAJAJARA).

O saber pintar o corpo com jenipapo, conforme mencionado por Zapuy Guajajara, ensina a prevenção e a cura das doenças e também ensina que o jenipapo é a verdadeira roupa do índio; em outras palavras, para os Tentehar, índio que é índio anda pintado. Portanto é uma marca da alteridade indígena. O estar pintado e o respeitar os mais velhos é pré-requisito indispensável para que o doente obtenha a cura através do ritual de mesada, afirmou Zapuy Guajajara. Nesse sentido, Brandão (2006, p. 18) considera que "o que se sabe aos poucos se adquire por viver [...] situações de trocas entre pessoas, com o corpo, com a consciência, com o corpo-e-a-consciência". O jenipapo é assim, um dos fluídos vitais, como o moqueado, que contribui para educar o corpo e a consciência da alteridade Tentehar.

Outro significado da pintura corporal entre os Tentehar diz respeito ao seu caráter camuflador. Por meio da pintura, os mais velhos ensinam aos jovens o saber disfarçar-se e proteger-se do inimigo, por isso também é conhecida como pintura de guerreiro, de acordo com Fred Guajajara. Segundo ele, os Tentehar mais velhos costumavam aconselhar os mais novos a andarem pintados, pois, com a pintura de guerreiro, a pessoa fica irreconhecível, fazendo com que o inimigo que chega à sua casa retorne à sua origem sem matar a possível vítima. Se antes os mais velhos usa- 
vam a pintura de guerreiro quando iam para a mata enfrentar algum povo rival, hoje a pintura de guerreiro é usada em manifestações, afirmou Fred Guajajara, "porque tem os inimigos que ficam observando, tal fulano que tá dando aquela entrevista, por isso que a gente se pinta, pra ninguém reconhecer".

O uso de jenipapo como tintura para proteção física ou espiritual, ou ainda como alimento, através do fruto ou do azeite, é uma marca da cultura tupi, que se configura pelo uso do alimento para manter-se saudável. O uso do jenipapo, portanto, simboliza um vasto conhecimento no uso da flora e fauna que os ameríndios dispõem para manter o corpo saudável, ou ainda curar-se ou proteger-se de algum mal por meio do uso de inúmeras plantas, dentre elas, o jenipapo.

\section{CONSIDERAÇÕES FINAIS}

Como povo originário das florestas, a base da vida material e religiosa dos Tentehar está nas matas, na natureza. É na floresta, por meio de práticas cotidianas, que tradicionalmente aprendem e dão sentido aos seus modos de viver e praticam suas diferentes formas culturais. Assim, as matas e a biodiversidade da terra indígena Arariboia constituem-se em um espaço vital para os Tentehar da aldeia Juçaral, visto que é nelas que residem os sentidos existenciais desse povo. Portanto, nas matas que estão fincados múltiplos saberes que desenvolvem no seu cotidiano, como o saber caçar, saber cantar, saber adornar-se, saber tecer redes, cestarias, saber curarem-se através plantas por intermédio ou não da pajelança, ou ainda, no repertório de histórias culturais em que interagem seres naturais e sobrenaturais, compondo o imaginário tentehar.

A forma de agradecer e reverenciar os espíritos e a natureza por todos esses saberes que lhes garantem a graça da vida é por meio dos seus rituais ou festas tradicionais. Logo, as festas de iniciação da menina moça, a festa do moqueado ou de apresentação da menina moça, a festa dos rapazes e a festa do mel podem ser compreendidas como mediadores culturais, indispensáveis à manutenção dos saberes culturais tradicionais tentehar, visto que nesses rituais circulam saberes cotidianos. Assim, os seus rituais promovem o enraizamento cultural reatualizando eventos do cotidiano e regras culturais, visto que evocam a memória e a identidade cultural dos Tentehar. Eles contêm a essência que subjaz ao ethos tentehar, a busca da relação harmoniosa entre natureza e sobrenatureza. Portanto comer os bolos de carne moqueada distribuídos na festa do moqueado, beber o mel durante a festa, ou 
pintar-se com o suco do jenipapo é provar do fluido vital que simboliza a reafirmação desse pacto de harmonia com o ecossistema que habitam.

\section{REFERÊNCIAS}

ABBEVILLE, C. D'. História da missão dos padres capuchinhos na ilha do Maranhão e terras circunvizinhas. Tradução de Sérgio Milliet. Brasília: Senado Federal, Conselho Editorial, 2008.

ALBUQUERQUE, M. B. B. Beberagens indígenas e educação não escolar no Brasil colonial. Belém, PA: FCPTN, 2012.

ANDRÉ, M. E. D. A. de. Etnografia da prática escolar. Campinas, SP: Papirus, 2007.

ANGROSINO, M. Etnografia e observação participante. Porto Alegre: Artmed, 2009.

BARROS, M. M. dos S.; ZANNONI, C. Reflexões sobre a festa do mel tenetehara. Cadernos de Pesquisa, São Luís, MA, v. 17, n. 1, p. 28-35, jan./abr. 2010.

BRANDÃO, C. R. O que é educação. São Paulo: Brasiliense, 2006. A educação como cultura. Campinas, SP: Mercado das Letras, 2002.

CASCUDO, L. da C. Dicionário do folclore brasileiro. 12. ed. São Paulo: Global, 2012.

CASTORIADIS, Cornélius. A instituição imaginária da sociedade. São Paulo: Paz e Terra, 1982.

CERRATINGA. Buriti. [s.d.]. Disponível em: <http://www.cerratinga.org.br/buriti>. Acesso em: 14 abr. 2017.

CHARLOT, B. Da relação com o saber: elementos para uma teoria. Porto Alegre: Artes Médicas Sul, 2000.

FARES, J. A. Cartografia poética. In: OLIVEIRA, I. A. de (Org.). Cartografias ribeirinhas: saberes e representações sobre práticas sociais cotidianas de alfabetizandos amazônidas. Belém, PA: EDUEPA, 2008. p. 101-110.

GEERTZ, C. A interpretação das culturas. Rio de Janeiro: LTC, 2012.

GHEDIN, E.; FRANCO, M. A. S. Questões de método na construção da pesquisa em educação. 2. ed. São Paulo: Cortez, 2011.

LÉVI-STRAUSS, C. O pensamento selvagem. 8. ed. Campinas, SP: Papirus, 1979.

LOUREIRO, J. de J. P. Olhar ontológico. In: MAUÉS, R. H.; VILLACORTA, G. M. (Org.). Pajelanças e religiões africanas na Amazônia. Belém, PA: EDUFPA, 2008. p. 357-60.

LOUREIRO, V. Amazônia: estado, homem, natureza. Belém, PA: CEJUP, 1992. 
MARTINS, J. de S. Sociologia da fotografia e da imagem. São Paulo: Contexto, 2008.

MCLAREN, P. Rituais na escola: em direção a uma economia política de símbolos e gestos na educação. Petrópolis, RJ: Vozes, 1992.

MUNDURUKU, D. O caráter educativo do movimento indígena brasileiro (1970-1990). São Paulo: Paulinas, 2012.

OLIVEIRA, I. A.; MOTA NETO, J. C. da. A construção das categorias de análise na pesquisa em educação. In: OLIVEIRA, I. A.; MARCONDES, M. I.; TEIXEIRA, E. (Org.). Abordagens teóricas e construções metodológicas na pesquisa em educação. Belém, PA: EDUEPA, 2011. p. 161-79.

PANTOJA, M. C. et al. O potencial do guarumã como bioadsorvente para remoção de metais em solução aquosa. 2015. Disponível em: <http://www.abq.org.br/cbq/2015/trabaIhos/5/7358-21143.html)>. Acesso em: 14 abr. 2017.

RIBEIRO DE SÁ, Maria José. Saberes culturais Tentehar e Educação Escolar Indígena na Aldeia Juçaral. 2014. Dissertação (Mestrado em Educação)- Universidade do Estado do Pará (UEPA), Belém, PA, 2014.

RODRIGUES, D. de S. S. et al. Cultura, cultura popular amazônica e a construção imaginária da realidade. In: OLIVEIRA, I. A. de; SANTOS, T. R. L. dos (Org.). Cartografias de saberes: representações sobre a cultura amazônica em práticas de educação popular. Belém, PA: Eduepa, 2007. p. 21-36.

SILVA, M. das G. et al. Cartografias e método(s): outros traçados e caminhos metodológicos para a pesquisa em educação. In: OLIVEIRA, I. A.; MARCONDES, M. I; TEIXEIRA, E. (Org.). Abordagens teóricas e construções metodológicas na pesquisa em educação. Belém, PA: EDUEPA, 2012. p. 59-78.

SZYMANSKI , H. (Org.). A entrevista na educação: a prática reflexiva. 4. ed. Brasília: Líber Livro, 2004.

VIVEIROS DE CASTRO, E. A inconstância da alma selvagem - e outros ensaios de antropologia. São Paulo: Cosac \& Naify, 2002.

WALGLEY, C.; GALVÃO, E. Os índios tenetehara (uma cultura em transição). Brasília: Ministério da Educação e Cultura, Departamento de Imprensa Nacional, 1961.

ZANNONI, C. Conflito e coesão: o dinamismo tenetehara. Brasília: Conselho Indigenista Missionário, 1999. 


\section{Sobre as autoras:}

Maria José Ribeiro de Sá: Mestre em Educação pela Universidade do Estado do Pará (UEPA). É graduada em Pedagogia pela Universidade Federal do Maranhão (2008). Possui especialização em Metodologia do Ensino Superior pela UEMA (2003) e bacharelado em Administração de Empresas pela Universidade Estadual do Maranhão (2001). É Pedagoga do Instituto Federal de Ciência e Tecnologia do Maranhão Campus Imperatriz, atuando no Departamento de Ensino Superior. Coordena atualmente o Núcleo de Estudos Afro-brasileiros e Indígenas do Campus Imperatriz. É membro do grupo de pesquisa em Ensino de Física e Astronomia, da Comissão de Avaliação de Projetos de Extensão. Coordena desde 2011 do projeto de extensão De Olho no Céu. Faz parte da comissão de normalização de produções científicas. É membro da comissão permanente de avaliação institucional- CPA; Tem experiência em Educação atuando principalmente nos seguintes temas: Educação Indígena, Educação Escolar Indígena, Educação Intercultural. E-mail: maria.sa@ifma.edu.br

Maria das Graças Silva: Socióloga, doutora em Planejamento Urbano e Regional (IPPUR/UFRJ), professora adjunta III da Universidade do Estado do Pará vinculada ao Programa de Pós-Graduação em Educação (PPGED/UEPA), coordena o grupo de Pesquisa Educação e Meio Ambiente (Grupema). E-mail: magrass@gmail.com

\section{Recebido em 30 de janeiro de 2017}

Aprovado para publicação em 22 de maio 2017 
